Diabetologia (1994) 37: 937-944

\title{
A gene in the HLA class I region contributes to susceptibility to IDDM in the Finnish population
}

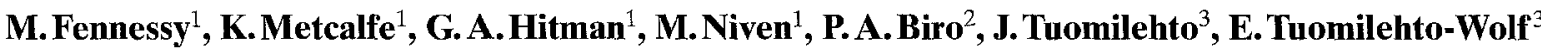 \\ and the Childhood Diabetes in Finland (DiMe) Study Group* \\ ${ }^{1}$ Department of Medicine, The Royal London Hospital, London, UK \\ ${ }^{2}$ Department of Immunology, The Royal London Hospital, London, UK \\ ${ }^{3}$ Department of Epidemiology and Health Promotion, National Public Health Institute, Helsinki, Finland
}

Summary In Finland the haplotype A2, Cw1, B56, DR4, DQ8 is the third most common haplotype in insulin-dependent diabetic (IDDM) patients and has the highest haplotype-specific absolute risk for IDDM. Cw1, B56, DR4, DQ8 haplotypes containing HLA-A alleles other than A2 are infrequent in the population and are not associated with IDDM. Comparison of the A2 and non-A2 haplotypes at the DNA level showed that they were identical at HLAB, -DR, and -DQ loci. Evidence that class I alleles confer susceptibility to IDDM was obtained from the two HLA-C, -B, -DR and -DQ haplotypes most frequently found in IDDM patients in Finland. A24, A3 and $\mathrm{A} 2$ on the Cw3, B62, DR4, DQ8 haplotype, and $\mathrm{A} 28, \mathrm{~A} 2$ and $\mathrm{A} 1$ on the Cw7, B8, DR3, DQ2 were all found to be associated with IDDM. In Finland these seven haplotypes, including A2, Cw1, B56, DR4,
DQ8, account for $33 \%$ of diabetic haplotypes and $10.3 \%$ of non-diabetic haplotypes $(p<0.00001)$. The contribution of the class I region to IDDM susceptibility was also apparent in those IDDM patients lacking the disease-predisposing class II alleles. Significantly more non-DR3/non-DR4 IDDM patients (47 of 55) possessed two of the IDDM-associated HLAA alleles compared to non-DR3/non-DR4 control subjects (40 of $58 ; p=0.038$ ). Moreover, IDDM patients confirmed by oligotyping as unable to form a 'diabetes-susceptibility' DQ heterodimer, tended to possess two diabetes-associated HLA-A alleles (12 of 13) compared to control subjects (12 of 20 ; $p=0.056)$. [Diabetologia (1994) 37: 937-944]

Key words Genetics, haplotype, HLA-A, HLA-DQ, HLA-DR, tumour necrosis factor, diabetes mellitus.
Received: 21 January 1994

and in revised form: 9 May 1994

Corresponding author: Dr. G. A. Hitman, Department of Medicine, The Royal London Hospital, Whitechapel, London E1 $1 \mathrm{BB}, \mathrm{UK}$

Abbreviations IDDM, Insulin-dependent diabetes mellitus; NIDDM, non-insulin-dependent diabetes mellitus; PCR, polymerase chain reaction; SSO, sequence specific oligonucleotide; TNF, tumour necrosis factor

\footnotetext{
* The Childhood Diabetes in Finland (DiMe) Study Group is composed of the following members:

Principal Investigators: H.K. Åkerblom, J. Tuomilehto.

Co-ordinators: R. Lounamaa, L. Toivanen.

Local Investigators: A. Fagerlund, M. Flittner, B. Gustafsson, C. Häggqvist, A. Hakulinen, L. Herva, P.Hiltunen, T. Huhtamäki, N.P.Huttunen, T.Huupponen, M.Hyttinen, T.Joki, R. Jokisalo, M.L.Käär, S.Kallio, E.A.Kaprio, U.Kaski,
}

Insulin-dependent diabetes mellitus (IDDM) is caused by an autoimmune destruction of the insulinproducing beta cells of the pancreas, the aetiology of which remains uncertain. Although a strong association exists between IDDM and markers in the HLADQ region of the major histocompatibility complex, HLA associations with IDDM were first described for the class I alleles HLA-B8, B18 and B15 (of which $\mathrm{B} 62$ is the major subtype) [1]. The higher relative risks of IDDM associated with DR3 compared to B8, and DR4 compared to B62, have been used as evidence to support the hypothesis that the primary susceptibility to IDDM exists in the class II region [2]. Highly poly-

M.Knip, L.Laine, J.Lappalainen, J. Mäenpää, A.L. Mäkelä, K.Niemi, A. Niiranen, A.Nuuja, P.Ojajärvi, T.Otonkoski, K.Pihlajamäki, S. Pöntynen, J. Rajantic, J.Sankala, J. Schumacher, M.Sillanpää, M.R.Ståhlberg, C.H.Stråhlmann, T. Uotila, M. Väre, P. Varimo, G. Wettenstrand. 
Table 1. Asociations of HLA-A alleles with IDDM on Cw1, B56, DR4, DQ8 haplotypes

\begin{tabular}{lllll}
\hline Haplotype & $\begin{array}{l}\text { Diabetic } \\
\text { haplotypes } \\
(n=1492(\%))\end{array}$ & $\begin{array}{l}\text { Non-diabetic } \\
\text { haplotypes } \\
(n=1254(\%))\end{array}$ & $\begin{array}{l}p \text { value. Diabetic } \\
\text { vs non-diabetic } \\
\text { haplotypes }\end{array}$ & $\begin{array}{l}\text { Corrected } \\
p \text { value }^{\mathrm{a}}\end{array}$ \\
\hline A2, Cw1, B56, DR4, DQ8 & $82(5.5)$ & $14(1.1)$ & $p<0.0001$ & $p<0.0004$ \\
A1, Cw1, B56, DR4, DQ8 & $3(0.2)$ & $1(0.08)$ & NS & NS \\
A3, Cw1, B56, DR4, DQ8 & $3(0.2)$ & $1(0.08)$ & NS & NS \\
A11, Cw1, B56, DR4, DQ8 & $1(0.1)$ & $0(0)$ & NS & NS \\
\hline
\end{tabular}

$p$ value generated by Fisher's exact test.

${ }^{a} p$ values were corrected for the number of haplotypes compared $(n=4)$

morphic markers are not ideal for population studies because individual allelic frequencies are so low that comparisons become meaningless. In this sense, HLA-DR serological and DNA HLA-DQ markers are ideal for association studies, whereas the class I HLA-B antigens are less useful, unless very large numbers of individuals are studied, because they are so polymorphic. However, because of linkage disequilibrium, each DR and DQ marker will be tightly associated with a number of class I antigens and these haplotypes are likely to be of similar discriminative value in association studies, as are individual alleles defined by the DQ locus. Indeed, Raum et al. [3] found associations of IDDM with four extended haplotypes: B8, SC01, GL02, DR3; B18, F1C30, DR3; B15, SC33, DR4; and B38, SC21, DR4. These associations were stronger than for DR3 or DR4 alone.

Finland has the highest incidence of IDDM in the world ( 35 of 100,000 per year in children aged 0 14 years) [4]. In the nationwide DiMe study 37 haplotypes, based on HLA-A, -C, -B, -DR and -DQ typing, have been found to be present in $84 \%$ (634 of 757) of the diabetic probands. The newly-described A2, Cw1, B56, DR4, DQ8 haplotype (abbreviated to A2, B56, DR4) which is present in $5.5 \%$ of diabetic haplotypes and $1.1 \%$ of non-diabetic haplotypes $(p<0.0001)$, has the highest absolute risk for IDDM (218 of 100,000 per year) compared to all other haplotypes [4] and is specific for the Finnish population, not being found in eight other European populations (Swedish [5], Norwegian [6], English [7], French [8, 9], Dutch [10], Estonian [11], Hungarian (E.Tuomilehto-Wolf, personal communication) and (former) East German [12] nor in the fourth and fifth Genetic Analysis Workshops [13-15]. In the Finnish population the Cw1, B56, DR4, DQ8 haplotype is a conserved haplotype and it is only associated with four HLA-A alleles; A2, A1, A3 and A11. Only the HLA-A2 associated haplotype is significantly increased in diabetes (Table 1) suggesting that on this haplotype at least the MHC class I region contributes to genetic susceptibility to IDDM.

HLA-DR3 and -DR4 containing haplotypes are strongly associated with IDDM in most ethnic groups, however, nearly $7 \%$ of IDDM patients in
Finland are non-DR3/non-DR4. Khalil et al. [16] proposed that aspartic acid at position 57 of the DQ $\beta$ chain and amino acids other than arginine at position 52 of the DQ $\alpha$ chain protect against IDDM, whereas arginine at position 52 of the DQ $\alpha$ chain and amino acids other than aspartic acid at position 57 of the $\operatorname{DQ} \beta$ chain lead to susceptibility to IDDM. A 'diabetes-susceptibility' DQ heterodimer is composed of a susceptible DQ $\alpha$ chain and susceptible $\mathrm{DQ} \beta$ chain. In the Finnish population there is a wide variation in IDDM predisposition in those individuals who can form a disease-associated DQ heterodimer according to which HLA class I alleles are present on the haplotype, ranging from the same as the background population (35 of 100,000 cases per year) to 218 of 100,000 cases per year [4]. Furthermore, $2.5 \%$ of Finnish IDDM patients do not possess 'susceptibility' alleles at both DQA1 and DQB1 and are therefore incapable of forming the 'diabetessusceptibility' DQ heterodimer. If genes in the class I MHC are important to disease predisposition, then patients who are non-DR3/non-DR4 or who are unable to form a 'diabetes-susceptibility' DQ heterodimer should demonstrate these associations.

The objectives of this study were to 1) characterize the A2, B56, DR4 haplotype at the DNA level and to compare this haplotype with non-A2, B56, DR4 haplotypes, 2) identify the HLA-A alleles that are most frequently found in haplotypes associated with IDDM and 3) compare these with the HLA-A alleles found in non-DR3/non-DR4 IDDM patients and IDDM patients who do not possess 'susceptibility' alleles at both DQA1 and DQB1.

\section{Subjects and methods}

Subjects. All individuals were taken from the "Childhood Diabetes in Finland" (DiMe) study $[4,17,18]$ a population-based prospective family study carried out in Finland between September 1986 and April 1989. A group of 757 newly-diagnosed diabetic children aged 14 years or younger and 112 control children matched with the early-onset diabetic patients (6 years and under, $n=122$ ) were HLA-A, -C, -B, -DR genotyped by serology together with their parents. The four haplotypes found in a family were divided into 'diabetic' and 'nondiabetic'. 'Diabetic' haplotypes were both haplotypes found 
in the proband, 'non-diabetic' haplotypes were those parental haplotypes found neither in the proband nor in diabetic parents nor diabetic siblings.

Sequencing of $M H C$ class I genes. PolyA ${ }^{+}$RNA was isolated by oligo (dT) cellulose (Invitrogen, San Diego, Calif., USA) batch adsorption from a Finnish A2, B56, DR4 Epstein-Barr virus transformed B-cell line. cDNA was synthesised [19] and the $\alpha 1$ to $\alpha 3$ regions (bases 97-808) of class I HLA genes were amplified from the cDNA by PCR with the primers 5'-CGAGAAGCTTGCTCCCACTCCATGAGGTATTTC$3^{\prime}$ and 5'-CCGGAGGATCCAGAAGGCACCACCACAG$3^{\prime}$. The PCR conditions were $50 \mathrm{pmol}$ of each primer, $50 \mathrm{mmol} / 1 \mathrm{KCl}, 20 \mathrm{mmol} / 1$ Tris-Cl $\mathrm{pH} 8.3,1.5 \mathrm{mmol} / 1 \mathrm{MgCl}_{2}$, $0.1 \mathrm{~g} / \mathrm{l} \mathrm{BSA}, 125 \mu \mathrm{mol} / 1 \mathrm{dNTPs}, 10 \% \mathrm{v} / \mathrm{v}$ dimethyl sulphoxide, 2 units Taq DNA polymerase (Perkin Elmer Cetus, Norwalk, Conn., USA) for 30 cycles of $94^{\circ} \mathrm{C}$ for $60 \mathrm{~s}, 50^{\circ} \mathrm{C}$ for $90 \mathrm{~s}$, $72^{\circ} \mathrm{C}$ for $120 \mathrm{~s}$. The amplification products were desalted using a Centricon concentrator (Amicon, Beverly, Mass., USA) and digested with Hind III and Bam HI restriction endonucleases, sites of which were incorporated into the PCR primers. Digested PCR products were extracted with phenol, excluded from Sephadex G50 (Pharmacia, Milton Keynes, UK) and then purified by electrophoresis in low gelling temperature agarose (FMC Bioproducts, Rockland, Md., USA). Purified digested products were ligated into bacteriophage M13mp18 and M13mp19 vectors which had been digested with Hind III and Bam HI restriction endonucleases. The ligated product was used to transform competent Escherichia coli JM109 [20]. Stocks of M13 clones were prepared [20] and dot blotted onto a Hyband-N+ nylon membrane (Amersham International, Amersham, Bucks., UK) following the manufacturer's recommendations. HLA-A clones were found to be in excess of the other class I clones. M13mp18 clones containing HLA-C and -B were identified using the oligonucleotide $5^{\prime}$ CCCAAAGACACACGTGAC-3' and M13mp19 clones containing HLA-C and -B were identified using the oligonucleotides 5'-TGCCTGGCGCTTGTACTTCTG-3' and 5'-TTCTA TCTCCTGCTGGTCT-3', respectively. Oligonucleotides were labelled with $\left[\alpha_{-}{ }^{32} \mathrm{P}\right]$ dCTP $(3000 \mathrm{Ci} / \mathrm{mmol}$ ) (Amersham International) using terminal deoxynucleotide transferase (Gibco BRL, Uxbridge, UK) following the supplier's recommendations and the membrane was hybridized with the oligonucleotides [20]. Using a Sequenase kit (USB, Cleveland, Ohio, USA) six M13 clones of HLA-A and -B in each orientation were sequenced and three clones of HLA-C genes were fully sequenced.

Typing of MHC class II loci. MHC class II genes were PCR amplified from proteinase $\mathrm{K}$ digested blood lysates [21]. Using protocols from the Eleventh International Histocompatibility Workshop [22] DRB1*04 and DQB1 alleles were PCR amplified, the product dot blotted onto Hybond-N+ nylon membranes and hybridized [20] with DRB1*04 and DQB1 SSOs which had been labelled with [ $\left.\alpha_{-}{ }^{32} \mathrm{P}\right] \mathrm{dCTP}$ using terminal deoxynucleotide transferase. DRB $1 * 04$ SSOs identified DRB $1 * 0401-* 0411$ inclusive. Any inconclusive typings at DQB1 were further analysed by PCR-RFLP [23]. DQA1 alleles were PCR amplified and typed either using an AmpliType kit (Perkin Elmer Cetus) or by PCR-RFLP [24].

$T N F \alpha$ microsatellite analysis and complement typing. The TNF $\alpha$ microsatellite was PCR amplified with 5 pmol of the primers IR2 5'-GCCTCTACTATTTCATCCAGCCACAG-3' and IR4 5'-CCTCTCTCCCCTGCAACACACA-3' [25] in a $10 \mu \mathrm{l}$ reaction containing $50 \mathrm{mmol} / \mathrm{K} \mathrm{KCl}, 10 \mathrm{mmol} / 1$ Tris-HCl pH $9.0,1.5 \mathrm{mmol} / 1 \mathrm{MgCl}_{2}, 1 \% \mathrm{v} / \mathrm{v}$ Triton X-100,
$0.5 \mu \mathrm{mol} / 1 \mathrm{dNTPs}, 1 \mu \mathrm{Ci}\left[\alpha^{32} \mathrm{P}\right](3000 \mathrm{Ci} / \mathrm{mmol}) \mathrm{dCTP}$ and 1 unit of Taq DNA polymerase. Amplification was for $15 \mathrm{cy}-$ cles of $94^{\circ} \mathrm{C}$ for $60 \mathrm{~s}, 64^{\circ} \mathrm{C}$ for $90 \mathrm{~s}$. Amplified product was electrophoresed on an $8 \% \mathrm{w} / \mathrm{v}$ acrylamide/bis-acrylamide (19:1) gel containing $48 \% \mathrm{w} / \mathrm{v}$ urea, $89 \mathrm{mmol} / 1$ Tris-borate, $2 \mathrm{mmol} / \mathrm{l}$ EDTA, the gel was then dried and autoradiographed. Complement Bf and $\mathrm{C} 4$ types were determined using immunofixation agarose gel electrophoresis [26, 27].

\section{Statistical analysis}

Statistical comparisons were by Chi square analysis employing a Fisher's exact two tailed test where appropriate. Corrected $p$ values were calculated by multiplying by the number of comparisons made; $p<0.05$ is taken as statistically significant.

\section{Results}

Characterization of the $A 2, B 56, D R 4$ haplotype. A2 and non-A2, B56, DR4 haplotypes were compared at the DNA level. The class I region was studied by sequencing, the class III region using the TNF $\alpha$ microsatellite and the class II region by oligonucleotide typing. HLA-A, $-\mathrm{C}$ and $-\mathrm{B}$ genes were sequenced on the A2, B56, DR4 haplotype. HLA-A and -C alleles on the A2, B56, DR4 haplotype were identical to $\mathrm{A}^{*} 0201$ and $\mathrm{CW}^{*} 0101$ [28]. HLA-B was identical to $B * 5601$ which had been previously sequenced on a non-A2, B56 haplotype (A1,3; Cw1; B8,56) [29].

TNF $\alpha$, a microsatellite located $3.5 \mathrm{~kb}$ telomeric to $\mathrm{TNF} \beta$, is highly polymorphic with fourteen alleles reported and a polymorphism information content (PIC) value of 0.86 [30]. Haplotypes with known associated TNF $\alpha$ alleles [30] were included as controls. Allele TNF $\alpha 6$ (sized $107 \mathrm{bp}$ ) was shown to segregate with the A2, B56, DR4 haplotype in five families. Allele TNF $\alpha 6$ was present in all 15 individuals tested with the A2, B56, DR4 haplotype (seven diabetic and eight non-diabetic) and all nine individuals tested with non-A2, B56, DR4 haplotypes (seven diabetic and two non-diabetic). The A2, B56, DR4 subject, from whom the class I sequence data had been derived, also possessed a TNF $\alpha 6$ allele. The complement typing of the A2, B56, DR4 haplotype was BFS, C4A3, C4B0.

DRB1*04 alleles in 16 individuals with the A2, B56, DR4 haplotype (nine diabetic and seven nondiabetic individuals) and nine individuals with the non-A2, B56, DR4 haplotype (seven diabetic and two non-diabetic individuals) were oligotyped and all possessed DRB1*0401.

DQA1 and DQB1 alleles in 14 individuals with the A2, B56, DR4 haplotype (seven diabetic and seven non-diabetic individuals) and nine individuals with the non-A2, B56, DR4 haplotype (seven diabetic and two non-diabetic individuals) were typed and all possessed DQA1*03, DQB1*0302. 
Table 2. Associations of HLA-A alleles with IDDM on Cw3, B62, DR4, DQ8 haplotypes

\begin{tabular}{|c|c|c|c|c|}
\hline Haplotype & $\begin{array}{l}\text { Diabetic } \\
\text { haplotypes } \\
(n=1492(\%))\end{array}$ & $\begin{array}{l}\text { Non-diabetic } \\
\text { haplotypes } \\
(n=1254(\%))\end{array}$ & $\begin{array}{l}p \text { value. } \\
\text { Diabetic vs } \\
\text { non-diabetic } \\
\text { haplotypes }\end{array}$ & $\begin{array}{l}\text { Corrected } \\
p \text { value }^{\mathrm{a}}\end{array}$ \\
\hline A28, Cw3, B62, DR4, DQ8 & $4(0.3)$ & $0(0)$ & NS & NS \\
\hline $\mathrm{A} 24, \mathrm{Cw} 3, \mathrm{~B} 62, \mathrm{DR} 4, \mathrm{DQ} 8$ & $17(1.1)$ & $3(0.2)$ & 0.006 & $<0.036$ \\
\hline $\mathrm{A} 2, \mathrm{Cw} 3, \mathrm{~B} 62, \mathrm{DR} 4, \mathrm{DQ} 8$ & $138(9.2)$ & $19(1.5)$ & $<0.0001$ & $<0.0006$ \\
\hline $\mathrm{A} 1, \mathrm{Cw} 3, \mathrm{~B} 62, \mathrm{DR} 4, \mathrm{DQ} 8$ & $3(0.2)$ & $2(0.2)$ & NS & NS \\
\hline $\mathrm{A} 3, \mathrm{Cw} 3 ; \mathrm{B} 62, \mathrm{DR} 4, \mathrm{DQ} 8$ & $41(2.7)$ & $9(0.7)$ & $<0.0001$ & $<0.0006$ \\
\hline \multirow[t]{2}{*}{$\mathrm{A} 11, \mathrm{Cw} 3, \mathrm{~B} 62, \mathrm{DR} 4, \mathrm{DQ} 8$} & $2(0.1)$ & $0(0)$ & NS & NS \\
\hline & $205(13.7)$ & $33(2.6)$ & & \\
\hline
\end{tabular}

$p$ value generated by Fisher's exact test.

${ }^{a} p$ values were corrected for the number of haplotypes compared $(n=6)$

Table 3. Associations of HLA-A alleles with IDDM on Cw7, B8, DR3, DQ2 haplotypes

\begin{tabular}{|c|c|c|c|c|}
\hline Haplotypes & $\begin{array}{l}\text { Diabetic } \\
\text { haplotypes } \\
(n=1492(\%))\end{array}$ & $\begin{array}{l}\text { Non-diabetic } \\
\text { haplotypes } \\
(n=1254(\%))\end{array}$ & $\begin{array}{l}p \text { value. } \\
\text { Diabetic vs } \\
\text { non-diabetic } \\
\text { haplotypes }\end{array}$ & $\begin{array}{l}\text { Corrected } \\
p \text { value }^{\mathrm{a}}\end{array}$ \\
\hline $\mathrm{A} 28, \mathrm{Cw} 7, \mathrm{~B} 8, \mathrm{DR} 3, \mathrm{DQ} 2$ & $29(1.9)$ & $6(0.5)$ & 0.0005 & 0.003 \\
\hline $\mathrm{A} 24, \mathrm{CW} 7, \mathrm{~B} 8, \mathrm{DR} 3, \mathrm{DQ} 2$ & $3(0.2)$ & $0(0)$ & NS & NS \\
\hline $\mathrm{A} 2, \mathrm{CW} 7, \mathrm{~B} 8, \mathrm{DR} 3, \mathrm{DQ} 2$ & $50(3.4)$ & $19(1.5)$ & 0.0021 & $<0.0126$ \\
\hline $\mathrm{A} 1, \mathrm{CW} 7, \mathrm{~B} 8, \mathrm{DR} 3, \mathrm{DQ} 2$ & $135(9.0)$ & $59(4.7)$ & $<0.0001$ & $<0.0006$ \\
\hline $\mathrm{A} 3, \mathrm{Cw} 7, \mathrm{~B} 8, \mathrm{DR} 3, \mathrm{DQ} 2$ & $11(0.7)$ & $4(0.3)$ & NS & NS \\
\hline \multirow[t]{2}{*}{$\mathrm{A} 11, \mathrm{CW} 7, \mathrm{~B} 8, \mathrm{DR} 3, \mathrm{DQ} 2$} & $4(0.3)$ & $2(0.2)$ & NS & NS \\
\hline & $232(15.5)$ & $90(7.2)$ & & \\
\hline
\end{tabular}

$p$ value generated by Fisher's exact test.

${ }^{a} p$ values were corrected for the number of haplotypes compared $(n=6)$

Association of $H L A-A$ alleles on $C, B, D R, D Q$ haplotypes with IDDM. Amongst haplotypes containing B56, DR4 only A2, B56, DR4 is associated with IDDM (Table 1). This haplotype is the third most abundant haplotype found in IDDM patients in Finland and yet it only accounts for $5.5 \%$ of diabetic haplotypes compared to $1.1 \%$ of non-diabetic haplotypes. To test if associations between HLA-A alleles and IDDM were a broader phenomenon, C, B, DR, DQ haplotypes based on the two most abundant diabetic haplotypes i.e., A2, Cw3, B62, DR4, DQ8 and $\mathrm{A} 1, \mathrm{Cw} 7, \mathrm{~B} 8, \mathrm{DR} 3, \mathrm{DQ} 2$, were similarly analysed. $\mathrm{A} 24, \mathrm{~A} 3$ and $\mathrm{A} 2$ on the $\mathrm{Cw} 3, \mathrm{~B} 62, \mathrm{DR} 4, \mathrm{DQ} 8$ haplotype (Table 2) and A28, A2 and A1 on the $\mathrm{Cw} 7, \mathrm{~B} 8$, DR3, DQ2 haplotype (Table 3) were associated with IDDM. These seven haplotypes, including the A2, $\mathrm{B} 56, \mathrm{DR} 4$ haplotype, associated with diabetes in the above analyses account for $33 \%$ of diabetic haplotypes and $10.3 \%$ of non-diabetic haplotypes (492 of 1492 diabetic haplotypes vs 129 of 1254 non-diabetic haplotypes; $p<0.00001)$, suggesting that certain HLA-A alleles (A28, A24, A2, A3 and A1) on these haplotypes are associated with an important factor in susceptibility to IDDM.

HLA class I in IDDM patients lacking HLA class II diabetes predisposing alleles. If the HLA class I is involved in disease predisposition it is most likely to be observed in those IDDM patients lacking the class II susceptibility alleles. HLA-DR3 and -DR4 are strongly associated with IDDM although it is the HLA-DQ regions in linkage disequilibrium with these HLA-DR antigens, DQA1*0501-DQB1*0201 and DQA $1 * 0301-\mathrm{DQB} 1 * 0302$, respectively, that are believed to confer the susceptibility [31]. Comparison of HLA-A alleles in non-DR3/non-DR4 probands and control subjects revealed that 47 of 55 probands compared to 40 of 58 control subjects $(p=0.038)$ possessed two copies of the IDDM-associated HLA-A alleles.

Amongst the non-DR3/non-DR4 IDDM patients 19 were identified, using the HLA associations listed in Table 4, who were unable to form a 'diabetes-susceptibility' DQ heterodimer. Of these patients, from whom genomic DNA was available, 13 were typed at DQA1 and DQB1 to confirm that they did not possess 'susceptibility' alleles at both loci (Table 5); nine did not possess a 'susceptible' allele at DQA1, three did not possess a 'susceptible' allele at DQB1 and one did not possess a 'susceptible' allele at either locus. Twelve of the 13 IDDM patients compared to 12 of 20 control subjects who were unable to form a 'diabetes-susceptibility' heterodimer $(p=0.056)$ possessed two alleles of either HLA-A28, A24, A3 or $\mathrm{A} 2$, all of which are associated with diabetes on at least one of the three haplotypes most frequently 
Table 4. Protective (DQA1 non-Arg 52, DQB1 Asp 57), (P) and susceptible (DQA1 Arg 52, DQB1 non-Asp 57), (S) DQA1 and DQB1 alleles associated with DRB1 alleles

\begin{tabular}{lll}
\hline DRB1 & DQA1 & DQB1 \\
\hline DR2 (15) & P 0102 & P 0602 \\
DR6 (13) & P 0103 & P 0603 \\
DR6 (14) & P 0101 & P 05031 \\
DR7 & P 0201 & P 0303 \\
DR1 & P 0101 & S 0501 \\
DR2 (16) & P 0102 & S 0502 \\
DR6 (13) & P 0102 & S 0604/0605 \\
DR7 & P 0201 & S 0201 \\
DR10 & P 0101 & S 0501 \\
DR4 & S 03011 & P 0301 \\
DR5 (11) & S 05012 & P 0301 \\
DR5 (12) & S 0501 & P 0301 \\
DR8 & S 0401 & P 0402 \\
DR9 & S 0302 & P 0303 \\
DR3 & S 05011 & S 0201 \\
DR4 & S 03011 & S 0302 \\
\hline
\end{tabular}

a HLA-B44 and -B51, DR4 haplotypes can be either DQB $1 * 0301$ or $* 0302$

Associations were generated by predicting DQA1 and DQB1 alleles from the Taq I, Pst I and Bam HI restriction fragment length polymorphism in DQA1 and DQB1 genes determined in 68 Finnish haplotypes [4]. The predictions are also based on the known linkage disequilibrium between specific alleles of the HLA-A, -C, -B, -DR and -DQ loci [22]

found in IDDM. Repeating this comparison but including the IDDM patients that have not been typed at DQ, then 17 of 18 are unable to form a 'diabetessusceptibility' DQ heterodimer ( $p=0.02$; Fisher's exact two-tailed test). Therefore, in those IDDM patients who do not possess the HLA-DQ alleles known to predispose to IDDM, certain HLA-A alleles are conferring susceptibility.

\section{Discussion}

Studies of the immune response in the pancreatic islets at IDDM onset implicate the HLA class I in pathogenesis. In human islets CD8 lymphocytes, which are MHC class I restricted, rather than CD4 lymphocytes, which are class II restricted, predominate at the time of disease onset [32] and when pancreatic grafts are rejected $[33,34]$. In the nonobese diabetic mouse CD8 lymphocytes are involved in the selective destruction of beta cells $[35,36]$ which could be prevented with anti-class I antibodies and anti-cytotoxic T-cell antibodies [37] and, furthermore, anticlass I antibody could prevent diabetes [38]. Hyperexpression of MHC class I molecules has been observed on all cell types in human pancreatic islets at onset of IDDM $[32,39]$ and rejection of xenogenic pancreatic islets can be prevented by antibodies directed against class I molecules [40]. However, peripheral blood lymphocytes from pre-diabetic (normoglycaemic) [41] and diabetic individuals [42] have reduced class I MHC expression. This phenomenon has been observed in other autoimmune diseases and may be a primary underlying defect leading to the failure of self-tolerance to develop.

A recent nationwide survey in Finland revealed a haplotype that had not been previously associated with IDDM. A2, B56, DR4 was the third most abundant haplotype in IDDM patients and carried the highest haplotype-specific absolute risk for IDDM compared to all other haplotypes. We have characterized this haplotype and compared it with non-A2, B56, DR4 haplotypes which are not found in increased frequency in diabetes. HLA-A, -B and -C sequences were identical to those found in Caucasians. The HLA-A allele A*0201 accounts for $89 \%$ of A2 allotypes found in Caucasians [43]. The published $B * 5601$ sequence was derived from a non- $A 2, C w 1$, B56 haplotype [29] and is identical to the sequence found on the A2, B56, DR4 haplotype. Since $\mathrm{CW}^{*} 0101$ was only sequenced on an A2, B56, DR4 haplotype and not on a non-A2, Cw1, B56 haplotype we cannot exclude a difference between A2 and non-A2 haplotypes existing at this locus. However, we feel that these two haplotypes are unlikely to differ at HLA-C because they are identical at the more polymorphic loci of HLA-B and -DR, and HLA-C has limited sequence polymorphism. Thus, there are no novel HLA-A, HLA-C or HLA-B sequences on the A2, B56, DR4 haplotype. All individuals with the B56, DR4 haplotype possessed the class II haplotype DRB1*0401, DQA1*03, DQB1*0302. A2 and non-A2 haplotypes from diabetic and non-diabetic individuals were typed at the class II loci using SSOs and PCR-RFLP methodologies. These have the limitation of only being able to identify characterized alleles. However, exon 2 of DQB1, which is arguably the single most important locus for conferring susceptibility to IDDM, had already been sequenced on the A2, B56, DR4 haplotype [4] and was identical to DQB1*0302. All individuals were DRB1*0401, DQA1*03, DQB1*0302. The DR4 subtyping on this highly diabetogenic haplotype is consistent with the report that the DRB $1 * 0401$ is the subtype most strongly associated with IDDM [44].

The MHC class III region was typed with a highly polymorphic microsatellite close to TNF $\beta$ because complotyping was not available on the non-A2, B56, DR4 haplotype. A2 and non-A2 haplotypes possessed the same microsatellite allele. Thus, there are no differences between the $\mathrm{A} 2$ and non-A2 haplotypes centromeric of HLA-B.

Having demonstrated that HLA-A alleles are markers of susceptibility to IDDM on one haplotype, we wanted to confirm that this locus would also act as a susceptibility marker on other haplotypes. A2, B56, DR4 is the third most abundant haplotype in IDDM and therefore, the two most abundant C, B, DR, DQ haplotypes were selected for analysis. 
Table 5. HLA-A, -DR and -DQ alleles in IDDM patients predicted and confirmed, or [ ] predicted only, as unable to form a 'diabetes-susceptibility' DQ heterodimer

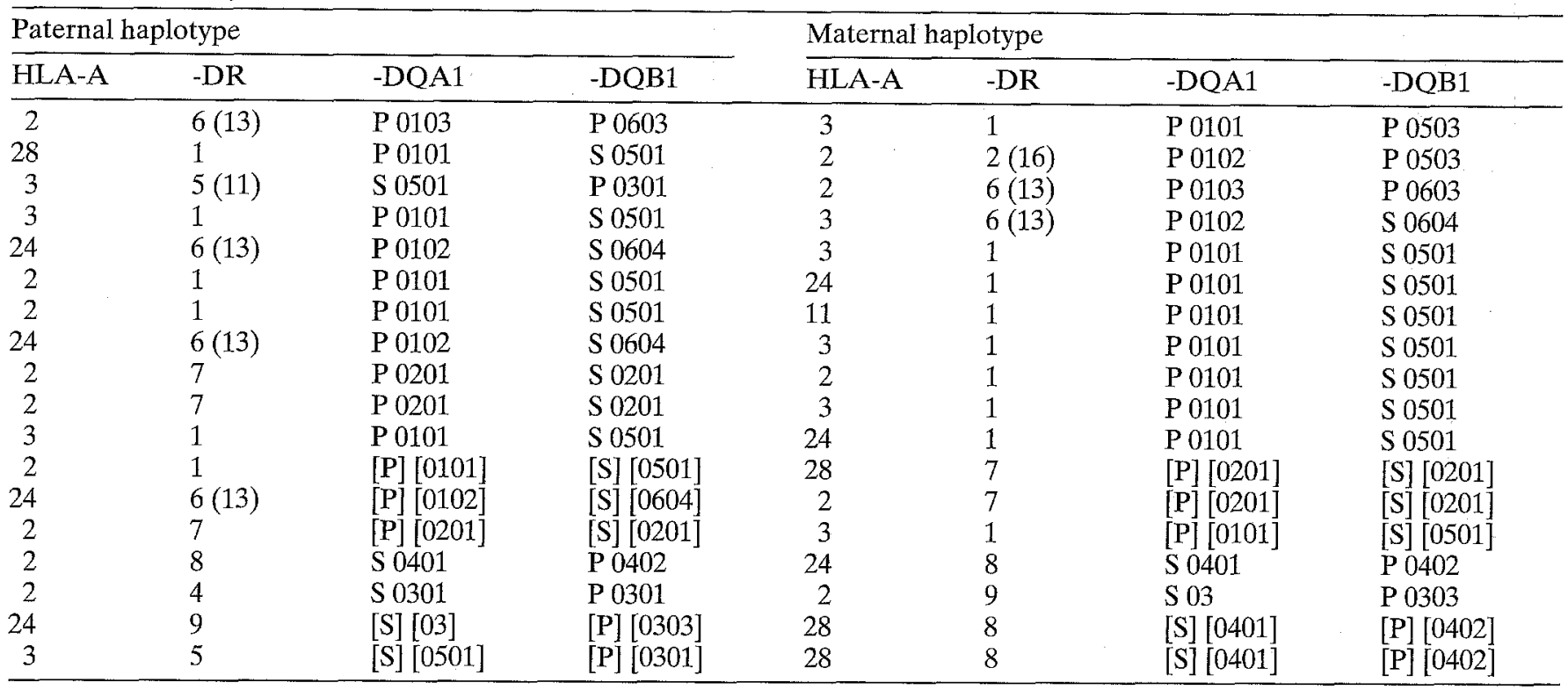

P, Protective; S, susceptible (refer to Table 4 for definition)

Cw3, B62, DR4, DQ8 and Cw7, B8, DR3, DQ2 haplotypes are heterogeneous at the HLA-A locus allowing comparison between HLA-A alleles and disease susceptibility. Comparison of HLA-A alleles on a predetermined $\mathrm{C}, \mathrm{B}, \mathrm{DR}, \mathrm{DQ}$ haplotype takes into account the known, and unknown, contribution these loci may make to disease susceptibility and assumes there is no variation at other MHC loci that influences disease susceptibility. It is especially important to control for the class II region which is well known to predispose to IDDM. Haplotypes containing certain HLA-A alleles were associated with diabetes and this was interpreted as conferring increased susceptibility to the disease. These IDDM-associated haplotypes are present in a third of Finnish diabetic patients.

An alternative approach to controlling for the class II genes is to examine HLA-A alleles in those patients that do not possess disease predisposing class II genes. Non-DR3/non-DR4 diabetic patients were more likely to possess two of the HLA-A alleles that increased susceptibility to diabetes on the three most abundant diabetic haplotypes. A similar tendency was noted in diabetic patients that could not form a 'diabetes-susceptible' DQ heterodimer.

Other studies have implicated the HLA-A region in diabetes. In Japanese IDDM patients HLA-A24 is associated with the acute onset of disease [45] and the complete loss of beta-cell function [46]. Also, there is an inverse association of HLA-A2 with age of disease onset in Pima Indians with NIDDM which is dose-related [47], and A2 was increased in South African blacks with NIDDM [48]. In all of these studies genes in linkage disequilibrium with HLA-A2 could in fact be contributing to the disease suscep- tibility. In Finland, HLA haplotypes which have a moderate association with IDDM are also strongly associated with mild glucose intolerance in elderly men [49]. However, haplotypes strongly associated with IDDM were rarely found in these individuals. This suggests a graded genetic susceptibility to diabetes depending on allelic variation of several genes on the MHC haplotype.

We have demonstrated that on the haplotypes most frequently found in IDDM which also contain the class II IDDM-associated alleles, the HLA-A alleles A28, A24, A3, A2 and A1 modulate the disease susceptibility. Furthermore, these HLA-A alleles may explain the existence of the disease in nonDR3/non-DR4 patients and patients who cannot form the 'diabetes-susceptibility' DQ heterodimer. We propose that a gene or genes in the class I region modulates the risk of IDDM in association with the class II 'diabetes-susceptibility' DQ heterodimers.

Acknowledgements. We thank the British Diabetic Association for generous funding of this work and the Human Genome Mapping Project for the use of TNF $\alpha$ PCR primers. We thank Dr. J.Partanen from the Finnish Red Cross Blood Transfusion Service, Helsinki, Finland for complement typing. Karl Metcalfe is a British Diabetic Association R.D.Lawrence Research Fellow. The DiMe study was supported by grants from the National Institute of Health, USA (NIH grant DK37957), from the Sigrid Juselius Foundation, the Association of Finnish Life Insurance Companies, the Nordisk Insulinfond and the Finnish Foundation for Diabetes Research. 


\section{References}

1. Cudworth AG, Woodrow JC (1976) Genetic susceptibility in diabetes mellitus: analysis of the HLA association. BMJ 2: $846-848$

2. Sachs JA, Cudworth AG, Jaraquemada D, Gorsuch AN, Festenstein H (1980) Type 1 diabetes and the HLA-D locus. Diabetologia 18: 41-43

3. Raum D, Awdeh Z, Yunis EJ, Alper CA, Gabbay KH (1984) Etended major histocompatibility complex haplotypes in type 1 diabetes mellitus. J Clin Invest 74: 449-454

4. Tienari PJ, Tuomilehto-Wolf E, Tuomilehto J, Peltonen L, and the DIME study group (1992) HLA haplotypes in type 1 (insulin-dependent) diabetes mellitus: molecular analysis of the HLA-DQ locus. Diabetologia 35: 254-260

5. Hägglöf $B$, Holmgren $G$, Holmlund $G$, Lindblom B, Olaisen B, Teisberg P (1986) Studies of HLA, factor B(Bf), complement $\mathrm{C} 2$ and $\mathrm{C} 4$ haplotypes in type 1 diabetic and control families from Northern Sweden. Hum Hered 36: 201-212

6. Ronningen KS, Spurkland A, Iwe T, Vartdal F, Thorsby E (1991) Distribution of HLA-DRB1, -DQA1 and -DQB1 alleles and DQA1-DQB1 genotypes among Norwegian patients with insulin-dependent diabetes mellitus. Tissue Antigens 37: 105-111

7. Wolf E (1989) Different linkage disequilibria in type 1 diabetic and 'healthy' HLA haplotypes. Pediatr Adolesc Endocrinol 18: 270-274

8. Contu L, Deschamps I, Lestradet H et al. (1982) HLA haplotype study of 53 juvenile insulin-dependent diabetic (IDD) families. Tissue Antigens 20: 123-140

9. Cambon-de Mouzon A, Ohayon E, Hauptmann G (1982) HLA-A, B, C, DR antigens, Bf, C4 and glyoxylase 1 (GLO) polymorphism in French Basques with insulin-dependent diabetes mellitus (IDDM). Tissue Antigens 19: 366-379

10. De Jongh BM, Bruining GJ, GMTH Schreuder et al. (1984) HLA and GM in insulin-dependent diabetes in the Netherlands: report on a combined multiplex family and population study. Hum Immunol 10: 5-21

11. Tuomilehto-Wolf E, Podar T, Adojan B, Kalits I, Tuomilehto J (1991) Can the difference in incidence of type 1 diabetes between Estonia and Finland be partly explained by genetic reasons? Diabetologia 24 [Supp1 2]: A65 (Abstract)

12. Rjasanowski I, Vogt L, Michaelis D, Keilacker H, Kohnert K (1993) The frequency of diabetes in children of type 1 diabetic parents. Diabete Metab Paris 19: 173-177

13. Genetic analysis of complex traits: insulin-dependent diabetes mellitus and affective disorders 1989 Proceedings of a workshop, Chantilly, France, September 2-5, 1987. Genet Epidemiol 6: 1-310

14. Hors J, Deschamps I, Schuler E (1986) Genetic Analysis Workshop IV: some clinical, pathological and etiological aspects of two HLA-related diseases. Genet Epidemiol 6 [Suppl 1]: 291-297

15. Thomson G, Robinson WP, Kuhner MK et al. (1988) Genetic heterogeneity, modes of inheritance, and risk estimates for a joint study of Caucasians with insulin-dependent diabetes mellitus. Am J Hum Genet 43: 799-816

16. Khalil I, d' Auriol L, Gobet M et al. (1990) A combination of HLA-DQ $\beta$ Asp 57-negative and HLA-DQ $\alpha$ Arg 52 confers susceptibility to insulin-dependent diabetes mellitus. J Clin Invest 85: 1315-1319

17. Tuomilehto-Wolf E, Tuomilehto J, Hitman GA and the DiMe study group (1992) DQA1 and DQB1 heterodimers in insulin-dependent diabetes mellitus. A genetic-epidemiology study in Finland. Ann Med 24: 533-538
18. Tuomilehto J, Lounamaa R, Tuomilehto-Wolf E et al. (1992) Epidemiology of childhood diabetes mellitus in Finland - background of a nationwide study of type 1 (insulindependent) diabetes mellitus. Diabetologia 35: 70-76

19. Kawasaki ES, Wang AM (1989) Detection of gene expression. In: Ehrlich HA (ed) PCR technology principles and applications for DNA amplification. Stockton Press, New York, pp 89-97

20. Sambrook J, Fritsch EF, Maniatis T (1989) Molecular cloning: a laboratory manual. 2nd edn. Cold Spring Harbor Laboratory Press, New York

21. Balnaves ME, Nasioulas S, Dahl H-HM, Forrest S (1991) Direct PCR from CVS and blood lysates for detection of cystic fibrosis and Duchenne muscular dystrophy deletions. Nucleic Acids Res 19: 1155

22. Tsuji K, Aizawa M, Sasazuki T (eds) (1992) HLA 1991. Proceedings of the eleventh international histocompatibility workshop and conference. Oxford Science Publications

23. Nomura N, Ota M, Tsuji K, Inoka H (1991) HLA-DQB1 genotyping by a modified PCR-RFLP method combined with group-specific primers. Tissue Antigens 38: 53-59

24. Maeda M, Murayama N, Ishii H et al. (1989) A simple and rapid method for HLA-DQA1 genotyping by digestion of PCR-amplified DNA with allele specific restriction enzymes. Tissue Antigens 34: 290-298

25. Nedospasov SA, Udalova IA, Kuprash DV, Turetskaya RL (1991) DNA sequence polymorphism at the human tumor necrosis factor (TNF) locus. Numerous TNF/lymphotoxin alleles tagged by two closely linked microsatellites in the upstream region of the lymphotoxin (TNF- $\beta$ ) gene. J Immunol 147: 1053-1059

26. Alper CA, Boenisch T, Watson L (1972) Genetic polymorphism in human glycine-rich beta-glycoprotein. J Exp Med 135: 68-80

27. Awdeh ZL, Alper CA (1980) Inherited structural polymorphism of the fourth component of human complement. Proc Natl Acad Sci USA 77: 3576-3580

28. Zemmour J, Parham P (1991) HLA class I nucleotide sequences, 1991. Tissue Antigens 37: 174-180

29. Hildebrand WH, Madrigal JA, Little AM, Parham P (1992) HLA-Bw22: a family of molecules with identity to HLAB7 in the o1-helix. J Immunol 148: 1155-1162

30. Jongeneel CV, Briant L, Udalova IA, Sevin A, Nedospasov SA, Cambon-Thomsen A (1991) Extensive genetic polymorphism in the human tumor necrosis factor region and relation to extended HLA haplotypes. Proc Natl Acad Sci USA 88: 9717-9721

31. Todd JA, Bell JI, McDevitt HO (1987) HLA-DQ $\beta$ gene contibutes to susceptibility and resistance to insulin-dependent diabetes mellitus. Nature (London) 329: 599-604

32. Bottazzo GF, Dean BM, McNally JM, MacKay EH, Swift PGF, Gamble DR (1985) In situ characterization of autoimmune phenomena and expression of HLA molecules in the pancreas in diabetic insulitis. N Engl J Med 313: 353-360

33. Sibley RK, Sutherland DER (1987) Pancreas transplantation an immunohistologic and histopathologic examination of 100 grafts. Am J Pathol 128: 151-170

34. Santamaria P, Nakhleh RE, Sutherland DE, Barbosa IJ (1992) Characterization of T lymphocytes infiltrating human pancreas allograft affected by isletitis and recurrent diabetes. Diabetes 41: 53-61

35. Hayakawa M, Yokono K, Nagata M et al. (1991) Morphological analysis of selective destruction of pancreatic $\beta$ cells by cytotoxic T lymphocytes in NOD mice. Diabetes 40: $1210-1217$

36. Nagata M, Yoon J-W (1992) Studies on autoimmunity for $\mathrm{T}$-cell mediated $\beta$-cell destruction. Distinct difference in 
$\beta$-cell destruction between $\mathrm{CD} 4{ }^{+}$and $\mathrm{CD} 8{ }^{+} \mathrm{T}$-cell clones derived from lymphocytes infiltrating the islets of NOD mice. Diabetes 41: 998-1008

37. Nagata M, Yokono K, Hayakawa M et al. (1989) Destruction of pancreatic islet cells by cytotoxic T lymphocytes in nonobese diabetic mice. J Immunol 143: 1155-1162

38. Taki T, Nagata M, Ogawa W et al. (1991) Prevention of cyclophosphamide-induced and spontaneous diabetes in NOD/Shi/Kbe mice by anti-MHC class I $\mathrm{K}^{\mathrm{d}}$ monoclonal antibody. Diabetes 40: 1203-1209

39. Foulis AK, Farquharson MA, Hardman R (1987) Aberrant expression of class II major histocompatibility complex molecules by $\mathrm{B}$ cells and hyperexpression of class I major histocompatibility complex molecules by insulin containing islets in type 1 (insulin-dependent) diabetes mellitus. Diabetologia 30: 333-343

40. Faustman D, Coe C (1991) Prevention of xenograft rejection by masking donor HLA class I antigens. Science 252: $1700-1703$

41. Faustman D, Li X, Lin HY et al. (1991) Linkage of faulty major histocompatibility complex class I to autoimmune diabetes. Science 254: 1756-1761

42. Fu Y, Nathan DM, Li F, Li X, Faustman DL (1993) Defective major histocompatibility complex class I expression on lymphoid cells in autoimmunity. J Clin Invest 91: 23012307
43. Van der Poel KJ, Pool J, Goulmy E, van Rood JJ (1983) Differential recognition of the serologically defined HLA-A2 antigen by allogeneic cytotoxic T cells. II. Definition of three HLA-A2 subtypes by CTLs. Immunogenetics 17 : 599-608

44. Sheehy MJ, Scharf SJ, Rowe JR et al. (1988) A diabetessusceptible HLA haplotype is best defined by a combination of HLA-DR and -DQ alleles. J Clin Invest 83: 830-835

45. Kobayashi T, Tamemoto K, Nakanishi K, Kato N, Okubo M (1993) Immunogenetic and clinical characterization of slowly progressive IDDM. Diabetes Care 16: 780-788

46. Nakanishi K, Kobayashi T, Murase Tet al. (1993) Association of HLA-A24 with complete $\beta$-cell destruction in IDDM. Diabetes 42: 1086-1093

47. Williams RC, Knowler WC, Butler WJ (1981) HLA-A2 and type 2 (insulin-dependent) diabetes mellitus in Pima Indians: an association of allele frequency with age. Diabetologia 21: 460-463

48. Briggs BR, Jackson WPU, Dutoit ED, Botha MC (1980) The histocompatibility (HLA) antigen distribution in diabetes in southern African blacks (Xhosa). Diabetes 29: $68-71$

49. Tuomilehto-Wolf E, Tuomilehto J, Hitman GA et al. (1993) Genetic susceptibility to non-insulin dependent diabetes mellitus and glucose intolerance are located in the HLA region. BMJ 307: 155-159 